EXPLORATION OF NURSES PRACTICAL SKILLS POST CESAREAN SECTION

\author{
AbuoShabana K. ${ }^{(1)}$, Reda A ${ }^{(2)}$,Samia I. ${ }^{(3)}$,Sally A. ${ }^{(4)}$ \\ ${ }^{(1)}$ Prof. of Maternity and Neonatal Nursing, Faculty of Nursing Ain Shams University. \\ ${ }^{(2)}$ Assistant Professor of Obstetrics and Gynecology, Faculty of Medicine, Mansoura University \\ ${ }^{(3)}$ Lecturer of Women's and Midwifery Health, Faculty of Nursing, Mansoura University \\ ${ }^{(4)}$ B.S.C Nursing, Faculty of Nursing, Mansoura University
}

\begin{abstract}
:
The aim of this studywas to explore nurses' practical skills post cesarean section. Methods: A descriptive exploratory design was carried out. Setting:Cesarean section rooms at obstetrics department of Mansoura University Hospital.Sample:26 nurses and 156 mothers post cesarean section. Tools:Three tools were used for data collection: An interview questionnaire schedule, Observational Checklist and Satisfaction Scale. Results:More than three quarter of nurses $(80.8 \%)$ were attained training course. Also, near to one fifth of nurses (19.2\%) were attained training course about nursing care provided post cesarean section. The majority of nurses $(96.2 \%)$ had correct knowledge about care provided post cesarean section. All nurses had incorrectly practiced post CS care for mothers and baby. And all mothers were not satisfied with nursing care provided post cesarean section.Conclusion: More than three quarter of nurses $(80.8 \%)$ were attained training course. Also, near to one fifth of nurses (19.2\%) were attained training course about nursing care provided post cesarean section. The majority of nurses $(96.2 \%)$ had correct knowledge about care provided post cesarean section. All nurses had incorrectly practiced post CS care for mothers and baby. And all mothers were not satisfied with nursing care provided post cesarean section.
\end{abstract}

Key words: Cesarean section, Nurse, Knowledge, Practice, Mothers' satisfaction

\title{
Introduction:
}

Labor is considered a normal physiological process, but sometimes due to some factors, intervention is needed to accomplish the process of labor and delivery. One of these interventions is cesarean section which means an operative procedure whereby fetus, is delivered through surgical incision on the abdominal and uterine walls (Jacob A, 2005, Basavanthappa, BT, 2006 and Pillitteri A. 2007).

A cesareanbirth was presented in clinical practice as safe procedure for both each mother and also baby. Although, this procedure carries risks for mother and baby,is sometimes essential for the safety of the mother or fetus when normal labor is contraindicated, Yet sometimes it may be on maternal request or it may be an emergency procedure to save the mother and/or fetus such as fetal distress, abruption placenta, a prolapsed cord, disproportion, total placenta previa, multiple pregnancies, cervical failure to progress and herpes. However, there is considerable debate 
about this type of cesarean that performed on the mother's request (Zakerihamidietal.,2015)

Moreover, cesarean delivery is most important operation done for women and it is observed that rate of cesarean delivery has intensely elevated in the past years. International estimates show that cesarean delivery rate of 15\% global.(Betran, 2007).

Additionally, Cesarean section causes many risks for the mother and fetus as compared with normal labor such as increase risk for losing of blood, expose to infection, increase risk of tearing the female reproductive organs as urinary bladder, uterine blood vessels, risk of tearing the uterine incision, risk of maternal death post cesarean labor from complications of anesthesia, puerperal infections, and deep vein thrombosis is 3.6 times higher for mother who have normal delivery (Mayberry, 2006, Towle, 2009 and Smith, 2010). Also, mother who have a cesarean delivery have a considerably increased risk of rehospitalization for endometritis, complications from medical wound as infection, and so on, complications from anesthesia, and cardiopulmonary and thromboembolic complications. Fetus deliver through cesarean labor is at considerably enlarged risks for respiratory complications and admission to the newborn ICU. (Mayberry, 2006 and Simpson, 2008).

Meanwhile, other maternal effects are considerably in favor of normal labor above cesarean delivery in the postpartum period. These risks include postpartum bleeding, elevated length of stay for mothers in hospital, and late

or diminished breastfeeding

(Mayberry, 2006; Simpson, 2008).

Also, women who had a cesarean delivery will need the similar nursing care such as the mothers who delivered normally, in addition routine postoperative care (Towle, 2009). Accurate nurses practical skills are a key factor in avoiding and treating such complication and the quality of nursing care and education have vital part in reducing complications of such operation and in assisting mother to good self- care and rise mother satisfaction(Smith, 2010).

However, nursing care facilities are the spinal column of the healthcare system in almost all nations in the world. They denote among $60-70 \%$ of the wellbeing personnel. So, It is essential to evaluate quality of nursing care provided to mothers and fetus post cesarean section that the nurses provide to mother and fetus in order to improve on it and to evaluate the nurse's performance post cesarean section based on a group of standards of care which are documented and developed by standard care. Thus it significant to have a well-trained nurse to offer accurate nursing care post cesarean section to avoid any problem to be arises.(Abdel-Kareem, 2008).

Moreover, nursehave an important role in supporting and educating post cesarean section consequences, not only as a health care provider but also as an administrator, care provider, educator, researcher and counselor(Abed El-ElAzim H, El Ngger N,Mansour S, 2012). 


\section{Significance of the study:}

Cesareanbirth was presented in clinical practice as safe procedure for both each mother and also baby. Although, this procedure carries many risks for the mother and fetus as compared with normal labor such as increase risk for losing of blood, expose to infection, increase risk of tearing the female reproductive organs as urinary bladder, uterine blood vessels, risk of tearing the uterine incision, Risk of maternal death post cesarean labor from complications of anesthesia, puerperal infections, and deep vein thrombosis is 3.6 times higher for mother who have normal delivery, rate is much higher than the adequate rate of $10-15 \%$ suggested by WHO(Zakerihamidietal., 2015).

In Egypt, rate of 1 delivery by CS was $47.25 \%$ in 2010 . This rate is greater than other rates estimated from different parts of the world, both in the developed and developing nations (Gibbons et al., 2012). So, Accurate nurses practical skills are a key factor in avoiding and treating such complication and the quality of nursing care and education have vital part in reducing complications of such operation and in assisting mother to good self- care and rise mother satisfaction (Smith, 2010). No previous study was accompanied at women's and midwifery health department faculty of nursing Mansoura university evaluating nursing practices post cesarean section so this study was conducted to evaluate of nursing practices post cesarean section.
Aim:

explore nurses' practical skills post cesarean section.

\section{Research Questions:}

- What are nurses knowledge about care provided post cesarean section?

- What are nurses' practical skills post cesarean sections?

- What is level of satisfaction regarding nursing care provided to mothers post cesarean section?

\section{Study design:}

Descriptive exploratory design

\section{Setting:}

The study was conducted on post cesarean section rooms at obstetrics department of Mansoura University Hospital from January 2014 to April 2014.

Type of sample:

For motherspost cesarean section(simple random sample) and for nurses (convenience sample)was used.

\section{Sample Size:}

All nurses worked in post cesarean section department total 26 nurses. Another sample included 161 mother calculated according to statistical equation

$$
n=\frac{M}{\left[\left(S^{2} \times(M-1)\right) \div p q\right]+1}
$$

\section{Sample Criteria:}

- All nurses worked in post cesarean section rooms within $1^{\text {st }}$ day post cesarean section.

- Mothers post cesarean sectionwere selected according to simple random sample. 
The sample technique:

- The researcher visited post cesarean section rooms three days each week from 9 am to $2 \mathrm{pm}$.

- Nurses were interviewed according to their sequences of their name in registration book the first 3 nurses interviewed individually daily.

Firstly, the goal of the present study was described to each nurse to attain her agreement to share in the study.

The length of meeting was $15-20$ minutes. 3 nurses were questioned every day. Interview questionnaire schedule used to assess nurses knowledge regarding nursing care provided post cesarean section.

Secondly,observational checklist was used to assess nursing care that provided to women and neonate.

Finally,satisfaction scale was used to assess level ofmothers' satisfaction regarding nursing care provided post cesarean section.

\section{Tools:}

Three tools

\section{First tool:}

An interview questionnaire schedule was established for the reason of data collection from nurses. It contained the present parts:

Part (I): It includes, general characteristics of nurses like age, years of experience, levels of education, did nurse attained training course? and what is the title of training course?

Part (II): Evaluated nurses' knowledge about care provided post cesarean section. It includes one open ended question and (15) multiple choose questions. Every question was assessed as correct $=(2)$ score and incorrect $=(1)$ score.
Total knowledge score was calculated as total correct more than $60 \%$ and less than $60 \%$ scored as incorrect knowledge.

\section{Second tool:}

Observational Checklist: Evaluation of nurses while they were practicing care for mother and baby post cesarean section. It includes 14 procedures. Every item in checklist procedure was evaluated as correct and incorrect practices.

Total nurses practical skills score was calculated as total correct more than $60 \%$ and less than $60 \%$ scored as incorrect practices.

\section{Third tool:}

Satisfaction Scale (Varghese \&Rajagopal, 2013): To evaluatelevel of mother's satisfaction regarding care provided by nurses post cesarean section.

It includes 24 items. Every item was assessed as satisfied, not satisfied and uncertainly dissatisfied.

Total mothers satisfaction score was calculated as satisfied $\geq 70 \%$, uncertainly dissatisfied $60-<70 \%$ and not satisfied $<60 \%$.

Tools revised by 3 experts of maternity nursing and according to their comments adjustments were considered.

\section{Operational Design:}

This study established different phases, the preparatory phase, the pilot study phase, field work, phase of analysis of data, phase of presentation of results in it is final form and discussion.

\section{Implementation phase:}

\section{The preparatory phase:}

Analysis of the previous and present local and intercontinental 
associated with literature by using books, articles and scientific journals was done by the researcher, this assisted the researcher to be familiar with the problem and guided in the process of tools designing, and the tools were then offered to specialists for assessment the validation.

\section{The pilot study phase:}

It was accompanied on 3 nurses and 21 mothers according to statistical analysis of pilot modification of the tool considered. It was carried out before beginning collection of the data. This was done in order to detect the time required to complete the tool. According to the pilot study the time required to finish the tool was calculated.

\section{Field Work:}

- The researcher was went to post cesarean section rooms three days per week from 9 am to $2 \mathrm{pm}$ during the period from January 2014 to April 2014.

- In the present study post cesarean section mothers were selected by using simple random sample and nurses were selected by using convenience sample.

- Firstly,Interview questionnaire schedule was used for interviewing nurses.

- The researcher was meeting every nurse on an individual basisto evaluate her knowledge about nursing care provided post cesarean section.

- Observational checklist was used to assessnurses' practical skills while providing nursing care for mother and baby post CS.
- The researcher was meeting every mother on an individual basisin the $2^{\text {nd }}$ day after cesarean delivery to evaluate mothers satisfaction regarding care provided to post cesarean section.

\section{Administrative Procedures:}

Formal written document agreement with explaining the reason from the study will be took from the head of obstetrics and gynecological department at Mansoura University Hospital as an agreement for collection of data to conduct this study.

\section{Ethical consideration:}

Before conducting the study the researcher attained on an agreement from the ethical agency at faculty of Nursing of Mansoura University. Moreover the researcher was attained on written agreement from administrator of Mansoura University Hospital to perform the study. Informed consent were attained from participant after clarifying the reasons of the study, each participant has right to withdraw from the study.

\section{Statistical Analysis:}

SPSS version 21 used to analyze data. Variables were offered into numbers and percentages test and mean standard deviation test.

\section{Results:}

Part I: General characteristics of the nurse: 
AbuoShabana K et. al.

Table (1): Distribution of nurses according to their general characteristics $(n=26)$

\begin{tabular}{|l|c|c|}
\hline Variables & No. & \% \\
\hline Age by years & 5 & 19.2 \\
\hline $18-25$ & 16 & 61.6 \\
\hline $25-30$ & 3 & 11.5 \\
\hline $30-40$ & 2 & 7.7 \\
\hline$>40$ &
\end{tabular}

Educational Level

\begin{tabular}{|l|l|l|}
\hline Diplom & 26 & 100.0 \\
\hline
\end{tabular}

Years of experience

\begin{tabular}{|l|c|c|}
\hline $1-5$ & 5 & 19.2 \\
\hline $6-10$
\end{tabular}

\begin{tabular}{|l|c|c|}
\hline $1-5$ & 5 & 19.2 \\
\hline $6-10$ & 16 & 61.6 \\
\hline $11-16$ & 2 & 7.7 \\
\hline
\end{tabular}

$11-16$

$\cdot 17$

Training courses

\begin{tabular}{|l|c|c|}
\hline No & 5 & 19.2 \\
\hline Yes & 21 & 80.8 \\
\hline
\end{tabular}

Title

\begin{tabular}{|l|c|c|}
\hline Nursing care post CS & 5 & 19.2 \\
\hline
\end{tabular}

\begin{tabular}{|l|l|l|}
\hline Infection prevention & 11 & 42.3 \\
\hline
\end{tabular}

\begin{tabular}{l|l|l|}
\hline Both courses & 10 & 38.5 \\
\hline
\end{tabular}

Table (2): Number and percent of nurses' knowledge regarding nursing care provided to mother and baby post cesarean section $(n=26)$

\begin{tabular}{|l|c|c|c|c|}
\hline \multicolumn{1}{|c|}{ Nurses' knowledge } & \multicolumn{2}{c|}{ Correct } & \multicolumn{2}{c|}{ Incorrect } \\
\cline { 2 - 5 } & No. & \% & No. & \% \\
\hline 1- Concept & 15 & 57.7 & 11 & 42.3 \\
\hline 2- Types & 18 & 69.2 & 8 & 30.8 \\
\hline 3- Indications for mother & 26 & 100.0 & - & - \\
\hline 4- Indications for baby & 26 & 100.0 & - & - \\
\hline 5- Complications for mother & 26 & 100.0 & - & - \\
\hline 6- Complications for baby & 26 & 100.0 & - & - \\
\hline 7- Teach mothers aboutadvantages of breast -feeding & 26 & 100.0 & - & - \\
\hline 8- Accuratediet for mother immediately after CS & 26 & 100.0 & - & - \\
\hline 9-Danger signs post cesarean section for mother & 22 & 84.6 & 4 & 15.4 \\
\hline 10- Danger signs post cesarean section for baby & 20 & 76.9 & 6 & 23.1 \\
\hline 11-Nursing role regarding cord stump care & 26 & 100.0 & 0 & 0.0 \\
\hline 12- Nursing practices that should providefor mother post CS & 11 & 42.3 & 15 & 57.7 \\
\hline 13- Nursing practices that should provide for baby post CS & 21 & 80.8 & 5 & 19.2 \\
\hline $\begin{array}{l}\text { 14-Preventive measures that nurse should be done if } \\
\text { hemorrhage was occurred post CS }\end{array}$ & 26 & 100.0 & - & - \\
\hline 15-Preventive measures for infection post CS & 26 & 100 & - & - \\
\hline 16- Hospital discharge information & 26 & 100 & - & - \\
\hline
\end{tabular}

Table (2) shows that (57.7\%) of nurses had correct answers about concept of cesarean section. All nurses had
Table (1) shows that (61.6) of nurse's age was ranged from 25-30 years. All nurses were had diploma education, and $(61.6 \%)$ of nurses had years of experience ranged from (6-10) years. Also, (19.2\%) of nurses were attained training course about nursing care provided post cesarean section.

Part II: Knowledge of nurse about nursing care provided post cesarean section

correct answers about indications of cesarean section for mother and baby. Also, $(69.2 \%)$ of nurses had correct 
answers about types of cesarean section, all nurses had correct answers about complications of cesarean section to mother and baby. In addition all nurses had correct answers about the nursing role regarding cord stump care, advantages of breast-feeding, hospital discharge information and diet for mother immediately post CS. $(84.6 \%)$ of nurses had correct answers about danger signs for mother post CS; while $(76.9 \%)$ of nurses had correct answers about danger signs for babypost CS.(42.3\%) of nurses had correct answers about nursing practices that should be provided for motherpost cesarean section; while $\mathrm{s}$ (80.8\%)of nurses had correct answer

Table 4: Distribution of correct and incorrect nurses' practical skills while

providing care to mother and baby post cesarean section $(n=26)$

\begin{tabular}{|c|c|c|c|c|}
\hline \multirow{2}{*}{ Nursing practices } & \multicolumn{2}{|c|}{ Correct } & \multicolumn{2}{|c|}{ Incorrect } \\
\hline & No. & $\%$ & No. & $\%$ \\
\hline \multicolumn{5}{|l|}{ General care for mother } \\
\hline Body temperature & 26 & 100.0 & - & - \\
\hline Pulse & 26 & 100.0 & - & - \\
\hline Respiration & 26 & 100.0 & - & - \\
\hline Blood pressure & 26 & 100.0 & - & - \\
\hline Perineal care & 23 & 88.5 & 3 & 11.5 \\
\hline Comfort measures & 14 & 53.8 & 12 & 46.2 \\
\hline \multicolumn{5}{|l|}{ Intake and output } \\
\hline Fluid intake & - & - & 26 & 100.0 \\
\hline Fluid output & - & - & 26 & 100.0 \\
\hline Bowel sounds & 26 & 100.0 & 0 & 0.0 \\
\hline Wound care & - & - & 26 & 100.0 \\
\hline Assessing urine for protein and sugar & - & - & 26 & 100.0 \\
\hline Lower extremities & - & - & 26 & 100.0 \\
\hline \multicolumn{5}{|l|}{ Breathing exercise } \\
\hline Pursed-Lip breathing & - & - & 26 & 100.0 \\
\hline Lateral costal excursion & - & - & 26 & 100.0 \\
\hline \multicolumn{5}{|l|}{ Foot and hand massage } \\
\hline Foot massage & - & - & 26 & 100.0 \\
\hline Hand massage & - & - & 26 & 100.0 \\
\hline Instructions for mother & 9 & 34.6 & 17 & 65.4 \\
\hline \multicolumn{5}{|l|}{ General care for baby } \\
\hline General hygiene (Baby bath) & - & - & 26 & 100.0 \\
\hline Cord stump care & 26 & 100.0 & - & - \\
\hline Technique of Breast-feeding & 26 & 100.0 & - & - \\
\hline Care of buttocks to avoid diaper rash & 5 & 19.2 & 21 & 80.8 \\
\hline
\end{tabular}

about nursing practices that should be provided for babypost cesarean section.

Table (3): Total nurses' knowledge score post cesarean section $(n=26)$

\begin{tabular}{|l|c|c|}
\hline $\begin{array}{l}\text { Totalnurses' } \\
\text { knowledge score }\end{array}$ & No. & $\mathbf{\%}$ \\
\hline Incorrect $<60 \%$ & 1 & 3.8 \\
\hline Correct $\geq 60 \%$ & 25 & 96.2 \\
\hline \multicolumn{2}{|l|}{ Total nurses' knowledge score (16) } \\
\hline
\end{tabular}

Table (3) illustrate that $(96.2 \%)$ of nurses had correct knowledge, while (3.8\%) had incorrect .

Part III: Nursing care provided to mother and baby post cesarean section 
Table (4): shows that all nurses had correctly practiced procedures (vital signs, bowel sounds, cord stump care for baby and technique of breastfeeding but $(88.5 \%)$ of nurses had correctly practiced procedure of perineal care. $(53.8 \%)$ of nurses had correctly practiced procedure of comfort measures. Only (19.2\%) of nurses had correctly practiced procedure care of buttocks. Also, all nurses had incorrectly practiced procedures ( wound care, assessing urine for sugar and protein, foot and hand massage, breathing exercise, lower extremities, and baby bathing).

Table (6 $\mathbf{6}_{\mathbf{a}}$ ):Mother's satisfaction regarding nursing care at the end of first day post $\mathrm{CS}(\mathrm{n}=156)$

\begin{tabular}{|c|c|c|c|c|c|c|}
\hline \multirow{2}{*}{ Items } & \multicolumn{2}{|c|}{ Satisfied } & \multicolumn{2}{|c|}{$\begin{array}{c}\text { Not } \\
\text { satisfied }\end{array}$} & \multicolumn{2}{|c|}{ Uncertainly dissatisfied } \\
\hline & No & $\%$ & No & $\%$ & No & $\%$ \\
\hline $\begin{array}{l}\text { 1-Nurse always kept the mother informed } \\
\text { before any procedures. }\end{array}$ & 46 & 29.5 & 57 & 36.5 & 53 & 34.0 \\
\hline $\begin{array}{l}\text { 2-Mother shares in choices related to her care } \\
\text { and care of baby. }\end{array}$ & - & - & 117 & 75.0 & 39 & 25.0 \\
\hline $\begin{array}{l}\text { 3- Nurse always promote emotional support for } \\
\text { mother }\end{array}$ & 76 & 48.7 & 65 & 41.7 & 15 & 9.6 \\
\hline 4- Provided mother care is in a safe manner & 66 & 42.3 & 24 & 15.4 & 66 & 42.3 \\
\hline 5-The nurses were sensitive $\&$ understandable & 49 & 31.4 & 61 & 39.1 & 46 & 29.5 \\
\hline $\begin{array}{l}\text { 6-Nurse always reserved privacy and during } \\
\text { providing nursing care for mother }\end{array}$ & 47 & 30.1 & 42 & 26.9 & 67 & 42.9 \\
\hline 7-Nurse give mother chances to ask questions & 33 & 21.2 & 64 & 41.0 & 59 & 37.8 \\
\hline 8-Nurse always listened to mother complains & 56 & 35.9 & 66 & 42.3 & 34 & 21.8 \\
\hline $\begin{array}{l}\text { 9-Nurse informed mother about hospital } \\
\text { discharge plan. }\end{array}$ & 33 & 21.2 & 90 & 57.7 & 33 & 21.2 \\
\hline
\end{tabular}

Table (5): Totalnurses' practical skills score that provided to mother and baby post cesarean section $(\mathrm{n}=26)$

\begin{tabular}{|l|c|c|}
\hline $\begin{array}{c}\text { Total nurses' } \\
\text { practical skills }\end{array}$ & No. & $\%$ \\
\hline Incorrect $<60 \%$ & 26 & 100.0 \\
\hline Correct $\geq 60 \%$ & - & - \\
\hline \multicolumn{3}{|c|}{ Total nurses' practical skills Score (147) } \\
\hline
\end{tabular}

Table (5) shows that total nurses practical skills score that provided to mother and baby post cesarean section. All of nurses had incorrect of nursing practices.

\section{Part III: Mothers' satisfaction regarding nursing care provided post cesarean section.}




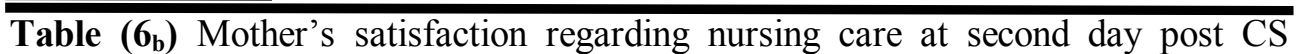
$(n=156)$

\begin{tabular}{|c|c|c|c|c|c|c|}
\hline \multirow[t]{2}{*}{ Items } & \multicolumn{2}{|c|}{ Satisfied } & \multicolumn{2}{|c|}{$\begin{array}{c}\text { Not } \\
\text { satisfied }\end{array}$} & \multicolumn{2}{|c|}{$\begin{array}{l}\text { Uncertainly } \\
\text { dissatisfied }\end{array}$} \\
\hline & No. & $\%$ & No. & $\%$ & No. & $\%$ \\
\hline $\begin{array}{l}\text { 10-Mother medication / treatment was } \\
\text { administered at proper time \&dose and } \\
\text { method }\end{array}$ & 62 & 39.7 & 40 & 25.6 & 54 & 34.6 \\
\hline $\begin{array}{l}\text { 11-The nurse checked mother vital signs } \\
\text { regularly. }\end{array}$ & 151 & 96.8 & - & - & 5 & 3.2 \\
\hline $\begin{array}{l}\text { 12-Nurse always she evaluates lochia flow } \\
\text { and informed mother about it. }\end{array}$ & 35 & 22.4 & 73 & 46.8 & 48 & 30.8 \\
\hline $\begin{array}{l}\text { 13-Nurse evaluated post cesarean section } \\
\text { incisional pain and intervene to relieve it }\end{array}$ & 31 & 19.9 & 64 & 41.0 & 61 & 39.1 \\
\hline 14-Nurse encourage early ambulation. & 133 & 85.3 & 22 & 14.1 & 1 & 0.6 \\
\hline $\begin{array}{l}\text { 15- Nurse encourage breast feeding technique } \\
\text { and improve mother to resolve breast } \\
\text { feeding problem }\end{array}$ & 54 & 34.6 & 46 & 29.5 & 56 & 35.9 \\
\hline $\begin{array}{l}\text { 16-Nurse educate mother about involution of } \\
\text { the uterus }\end{array}$ & - & - & 156 & 100 & - & - \\
\hline $\begin{array}{l}\text { 17-Nurse informed mother about diet, sleep } \\
\text { and rest in post cesarean section }\end{array}$ & 41 & 26.3 & 56 & 35.9 & 59 & 37.8 \\
\hline $\begin{array}{l}\text { 18-Nurse instruct mother about the methods \& } \\
\text { importance of family planning }\end{array}$ & - & - & 155 & 99.4 & - & - \\
\hline $\begin{array}{l}\text { 19-Nurse educate mother about baby diaper } \\
\text { care and baby daily bath }\end{array}$ & - & - & 104 & 66.7 & 52 & 33.3 \\
\hline $\begin{array}{l}\text { 20-Nurse instruct mother for detection for } \\
\text { danger signs }\end{array}$ & 60 & 38.5 & 58 & 37.2 & 38 & 24.4 \\
\hline $\begin{array}{l}\text { 21-Nurse instructed mother about cord stump } \\
\text { care }\end{array}$ & 141 & 90.4 & - & - & 15 & 9.6 \\
\hline $\begin{array}{l}\text { 22-Nurse instruct mother how to detect sign } \\
\text { and symptoms of infection }\end{array}$ & 12 & 7.7 & 66 & 42.3 & 78 & 50.0 \\
\hline $\begin{array}{l}\text { 23-Nurse instruct mother how to keep wound } \\
\text { dry and clean to prevent wound infection }\end{array}$ & 45 & 28.8 & 54 & 34.6 & 57 & 36.5 \\
\hline $\begin{array}{l}\text { 24-Nurse instruct mother about baby } \\
\text { vaccination and regular follow up during } \\
1^{\text {st }} \text { year of life }\end{array}$ & 15 & 9.6 & 117 & 75.0 & 24 & 15.4 \\
\hline
\end{tabular}

Tables $\left(6_{\mathrm{a}}, 6_{\mathrm{b}}\right)$ demonstrate the mothers' satisfaction regarding nursing care provided post cesarean section. It includes (1)Mother's satisfaction regarding nursing care at the end of first day post CS according to the table $\left(6_{a}\right)(48.7 \%)$ of mothers were satisfied with (Nurse always promote emotional support for mother). While there were no mothers satisfied with (Mother shares in choice related to her care and care of baby). (2)Mother's satisfaction regarding nursing care at second day post CS according to the table $\left(6_{b}\right)(96.8 \%)$ of mothers were satisfied with (The nurse checks mother vital signs regularly). While there were no mothers satisfied with (Nurse instructs mother about involution of the uterus, nurse instructs mother about the methods \& importance of family planning and nurse instructs mother about baby diaper care and baby daily bath). 
Table (7): Total mothers' satisfaction score regarding nursing care provided post cesarean section $(\mathrm{n}=156)$

\begin{tabular}{|l|c|c|}
\hline $\begin{array}{l}\text { Total Mothers' } \\
\text { satisfactionScore }\end{array}$ & No. & \% \\
\hline Not satisfied $<60 \%$ & 156 & 100.0 \\
\hline $\begin{array}{l}\text { Uncertain dissatisfied } \\
60-<70 \%\end{array}$ & - & - \\
\hline Satisfied $\geq 70 \%$ & - & - \\
\hline
\end{tabular}

Table (7) indicate that all mothers were not satisfied regarding nursing care that provided post cesarean section.

\section{Discussion}

The goal of the present study was to explore nurses practical skills post cesarean section. This aim significantly was achieved through the present study research question, because it was observed that the majority of nurses had correct knowledge regarding caesarean section while all of them incorrectly practices post caesarean section care. This result of the present study finding was agreed with the study of AbdEIrahman, (2012) in SobaUniversity Hospitalwhostated that the majority of nurses had good knowledge about caesarean section $(98 \%)$. Nevertheless, the results showed poor nursing practices in post caesarean section care. This is might be due to shortage number of nurses in one shift as well as heavy work, overload from orders of the doctor, the great amounts of admission daily, and finally due to lack of continuous in-service and bedside training .

It was reported by Simbar et al, (2009) in Kordestan Medical Science University hospitalsthat, Egyptian nurses in governmental hospitals were suffering from shortage number of nurses in one shift, overload from orders of the doctor, the great amounts of admission daily, small salaries compared to the quantity of duties needed from nurses, inflexible schedules of the work in addition to shortage of supplies, all impose them to offer the important routine nursing practices in a tense mode that effects on the quality of nursing care. These results were agreed with the present study which it was showed that all of nurses in Mansoura University Hospital incorrectly practices post caesarean section care due to lack number of nurses in one shift as well as heavy work, overload from orders of the doctor, the great amounts of admission daily, small salaries compared to the quantity of duties needed from nurses, inflexible schedules of the work in addition to shortage of supplies and equipment, all of these causes were lead to nurses did not provide high quality of nursing care and also lead to mothers not satisfied about nursing care that provided for them.

Mothers who deliver by cesarean section have an additional care during postpartum period, because they are not postpartum mothers but postoperative ones as well. Nursing care is combined aspects of surgical and maternity care (Pillitteri, 2007). The nursing goal for mother who has cesarean section is to promote comfort and relieve pain. Post-partum mother need to be comfortable alert to parent, to their infants, assumes self-care and baby care (U.S. Department of Health and Human Resources, 2003). 
Ladewiget et al., (2008) in New Yorkstated that, when the mothers return to the nursing ward postoperative, the nurse is responsible for observed their general condition, vital signs are assessed and recorded until mothers condition are stable). This is agreed with findings of the present study which showed that all nurses in Mansoura University Hospital correctly measuring vital signs.

As regardingBurunner et al., (2009) in USAstated that the nurse must covered the skin around the drains or tubes with sterile gauze to prevent infection, dressing should not be changed or reinforced unless there are doctor orders.

Castiglia and Harbin, (2009) stated that wet dressing can increase the possibility of infection: while clean and dry dressing increase the mothers comfort. This result disagreed with the result of the present study which observed that all nurses in Mansoura University Hospital were incorrectly practiced wound care procedure.

Elander et al, (2009) they reported that nursing responsibility that help in alleviating pain post cesarean section include comfort measures and this result disagreed with findings of the present study showed that more than half of nurses $(53.8 \%)$ help post cesarean section mothers to reduce post CS pain by comfort measures. Because Egyptian nurses are responsible for all administrative aspect in the epartment beside her technical role.

The present study revealed that all nurses in Mansoura University Hospital were incorrectly measuring and recording intake and output (I\&O) chart for 24 hour. This is disagreed with study by Fox, (2010) in Network who stated that one of the most essential roles of the nurse in keeping fluid balance is accurate measurement of intake and output, accurate intake is essentialpost cesarean section to replace losing of blood from the procedure to preserve blood pressure and function of the kidney. Keeping on an adequate fluid intake and output best for at least the initial 24 hours to determine an accurate fluid balance.

As regard nurses' practices of postcesarean section exercise (breathing and leg) it was found that in the present study that all nurses in Mansoura University Hospital were incorrectly done breathing and leg exercise. Due to lack of monitoring nurses practical skills at Mansoura University Hospital. This findings of the present study disagreed with study done by Joan \&Mik, (2010) who stated that postoperative nursing measures that contribute to the prevention of respiratory complications. Through practiced frequent deep breathing, coughing and turning are required.

Also, Jamieson et al., (2010) inUSAreported that in order to prevent poor air exchange and to maintain adequate ventilation the nurse should begin aggressive pulmonary hygiene early. The benefits of preoperative teaching are realized when the patient is able to participate actively. Diaphragmatic breathing should be exercised minimal eachtwo hours howeverawake, highest inspiration lasting 3:5 seconds will open up alveoli 
AbuoShabana K et. al.

Mason et al., (2008) inUSA mentioned that, if the mother feels that the incision is painful, a pillow can be used to support the dressing site.

The present study finding reported that all nurses encouraged mothers for early ambulation: this is agreed with Beck, (2006) in Hong Kong who reported that the nurse promotes early ambulation and physical activity to stimulate a return of peristalsis and helps in relief of abdominal distention. Ambulation helps the gas to move along the intestine so that it can expel The present study finding reported that all nurses correctly auscultated bowel sounds. This agreed with Farouk et al., (2013) in Egyptthey mentioned that the nurse routinely auscultate the abdomen to detect the returning of usual bowel sounds and monitor acceptance of ordered diet after surgery, diet progress from clear fluids to full fluids and from soft to regular.

Regarding instructed mothers for early initiation of breast-feeding technique and position of breast-feeding. The present study finding was revealed that all nurses were correctly instructed all mothers about this issues. Breastfeeding is culturally and religiously recommended in our Egyptian community. This is agreed with Neef\& Spray, (2006) inNew York, who mentioned that the nurse is responsible about educating mother how hold and feed her baby. Also, the nurse provides all postpartum instruction to mother bout self-care and care of her baby.

As regard different pain relief measures to reduce post cesarean section pain as making foot and hand massage it was found that in the current study the nurses were practiced incorrectly the different pain relief measures in Mansoura University Hospital, this results disagreed with the study done by Degirmen et al., (2010) on Turkish post cesarean section mothers, they stated that, 20 minutes massage for foot and hand reduced discomfort post cesarean section within the first 24 hours after cesarean section. These measures incorrectly practices by nurses in Mansoura University Hospital because there is no training programs was conducted regarding this issue.

Sally, (2008) mentioned that, perineum must be observed for passage of clots and amount of bleeding and nurse must be cleanse the perineum and apply clean perineal pad. This is agreed with present study because it was reported that the majority of nurses were correctly practiced perineal care procedure.

Abed El-Azim, El Ngger\& Mansour, (2012) in Egyptreported that one of the important nursing roles in postpartum period are carrying out health education. Health education about nutrition, exercises, family planning, warning signs of post cesarean section and the importance of day 40 checkup. Also, nurse should be instruct mothers about (care of mouth, care of eye, care of skin, cord stump care, vaccination, and warning signs regarding baby). This is agreed withthe finding of the present study which was found that, more than one third of nurses were provide mothers post cesarean section instructions about family planning, nutrition, exercise, hygiene for mother and baby and first year vaccination schedule. Also, it was found that all 
nurses in post cesarean section ward had good knowledge about instructions that should be given to mothers before discharge.

Also, Abed El-Azim, El Ngger\&

Mansour (2012) in Egypt they stated that Large number of women were not satisfied with nursing practices that provided to them in postpartum period. However, they received very brief information, did not participate in decision associated with nursing care of their baby and themselves, they were not prepared enough for discharge as well as more than two thirds of mothers stated that there was no opportunities to ask questions and the nurse didn't listen carefully to their complains. These results were agreed to findings of the present study which was found that all mothers in Mansoura University Hospital were not satisfied from nursing practices that provided for mothers post CS. Because they did not share in choices associated withnursing care of their children and themselves, did not oriented about rules and regulations of visiting hours, time of medication, dressing and nutrition and they were not prepared enough for discharge. Mothers stated that nurse did not instruct them about these issues (involution of the uterus and baby diaper care and baby daily bath, how to maintain wound clean and dry to prevent infection of the wound and vaccination of the child and consistent follow up through $1^{\text {st }}$ year of life). Also, nurses did not instruct mothers about methods, importance of family planning and follow up visits because our culture and tradition in rural area disagree with the utilization of family planning methods.

\section{Conclusion:}

More than three quarter of nurses $(80.8 \%)$ were attained training course. Also, near to one fifth of nurses $(19.2 \%)$ were attained training course about nursing care provided post cesarean section. Majority of nurses $(96.2 \%)$ had correct knowledge, (3.8\%) had incorrect knowledge about nursing care provided post cesarean section.Yet, all mothers were not satisfied regarding nursing care that provided for them.

\section{Recommendations:}

1- Pre-service and in-service training programs about post cesarean section care must be designed and implemented for all nurses.

2- Establishing staff development unit at obstetrics and gynecology department in Mansoura University Hospital to monitor and enhance nurses' practical skills.

3- Dissemination of the present study findings to obstetrics and gynecology department at Ministry of Health Hospitals and Mansoura University Hospital.

\section{References:}

Abed El-Azim H, El Ngger N,Mansour S., (2012): Women' perspectives regarding the quality of postpartum nursing care in Ain Shams Maternity Hospital. Cairo, Egypt 367.

Abdel-Kareem, S. (2008): Factors Affecting the Quality of Nursing Care in Intensive Care Unit: Perception of Physicians and Nurses Versus Health Care Consumers (Master thesis), Ain Shams University, Cairo, 2008. 


AbdEIrhman H., (2012): Assessment
of knowledge and practice of
nurses regarding post cesarean
section care in soba university
Hospital Friday, Cross Sectional
study, RCRU Reproductive and
Child Research Unit, 27 July
2012 06:50.
Basavanthappa BT., (2006):
Textbook of midwifery
\&reproductive health nursing.
New Delhi: BT Basavanthappa
Beck N. M., (2006): Nutrition and
dietetics for nurses, 7 thEdn
Churchill Livinggston, Hong
Kong, PP204- 8.
BetranBetran AP, Merialdi M,
Lauer JA, Bing-Shun W,
Thomas J, Van Look P, et al.,
(2007): Rates of caesarean
section: analysis of global,
regional and national estimates.
Paediatric and Perinatal
Epidemiology;
21(2):98-113.

Brunner L, Suddarth D., (2009): Textbook of medical surgical nursing 5 thEdn. J B Lippincott Co., Philadelphia, London, USA, PP 1418- 42

Castigilia PT and Harbin Re., (2009): Child Health Care: Process Practice Philadelphia JB Lipincott, 2009

Jacob A. (2005): A comprehensive textbook of midwifery. New Delhi: Annamma Jacob

Degirmen, N., Ozerdogan, N., Sayiner, D. and et al., (2010): Effectiveness of Foot and Hand Massage in Post Cesarean Pain Control in a Group of Turkish Pregnant Women. Applied Nursing Research 23: 153-158.
Elander G, Hellstrom $G$ and Quarnstrom B., (2009): Pediatric Nursing, vol 1 - 19, No 3, 2009

Farouk M, Nagieb S, Mohamed M., (2013): Ideal Nursing Care Relationship between Assuit University Hospital and King Fahd Hospital Gizan Hospital among post Cesarean section care.AAMJ, Vol. 11, N. 2, April, 2013.

Fox DM., (2010): Measurement of urine output volume: accuracy of diaper weights in neonatal environments. Network, 11(3): 11- 18, 2010.

Gibbons L, Belizan J, LauerJ, Betran A, Merialdi M., (2012): Inequities in the use of cesarean section deliveries in the world. AM J Obstet Gynecol. 206: 331

Jacob A., (2005): A comprehensive textbook of midwifery. New Delhi: Annamma Jacob.

Jamieson ME, Mc Call MJ, Blyth K., (2010): Clinical nursing practice. Longman Churchill Livingstone, Edinburgh, London, New York USA, PP $590-7$ 2010

Joan A and Mike BA., (2010): Watsons medical Surgical Nursing Related Physiology Fourth Edition, 2010

Ladewig P.W, London M. $L$, and Olds S.B., (2008): Maternal Newborn Nursing care, the nurse, the family, and the community, 4 thEdn, Adison. Wesley longman, New York, P.P. 495

Mason Ma, Bates G f., (2008): Basic medical surgical nursing. 5 
thEdn. Mac Millan Publishing, New York, Toronto, USA, P 562, 2008

Mayberry, L., (2006): Cesarean delivery on maternal request. Nursing Implications of the 2006 NIH. State of the Science Conference Statement, MCN (Special Report for MCN), Vol.32, No.5, pp. (286-89),. ISSN: 1539-0683.

Neef M.C, \& Spray M., (2006): Introduction to maternal and child health nursing, Lippincot Philadelphia, New York, P.P. $213-222$

Pillitteri A., (2007): Maternal \& child health Nursing:care of the childbearing \& childrearing family. 5thed.Philadelphia: Adele Pillitteri

Sally B., Marcial L. London,Patricia A. Ladewig., (2008): Maternal Newborn Nursing. 3 rdEdn.(2008) Addison- Wesley Publishing Company.P.P. 800: 818.

Simbar, M., F. Ghafari, S., T. Zahrani and H., A. Majd., (2009): Assessment of quality of midwifery care in labor and delivery wards of selected Kordestan Medical Science
University hospitals. International Journal of Health Care Quality Assurance, 22(3):266-277.

Simpson, K.R., (2008): labor and birth, In: Perinatal Nursing, (Third edition), Kathleen Rice Simpson and patricia A. Creehan, (Eds.), pp.(300- 375), Lippincott Williams \&Wilkings, ISBN-13: 978-0-7817-6759-0. Phidelphia, USA.

Smith, L.J., (2010): Impact of Birth Practices on Breastfeeding, (Second edition), Jones and Barlett Publishers, ISBN 978-07637-6374-9, Sudbury, USA.

U.S. Department of Health and Human Resources.,(2003): Monthly Vital Statistics report: CDC and prevention was hington, DC: National center for health statistics. Vol 42, No. 2 (suppl)

Zakerihamidi M, Latifnejad Roudsari R, Merghati KhatiKhoei E., (2015): VaginalDelivery Vs. Cesarean section: A focused Ethnographic Study of Women's Perceptions in The North of Iran. Int J Community Based Nursing Midwifery. 3 (1): 39-50 